\title{
Livros
}

\section{Bases Biológicas dos Transtornos Psiquiátricos} Flávio Kapiczinsk, João Quevedo e Ivan Izquierdo. Porto Alegre: Artes Médicas Sul. 2000. 271 páginas. ISBN-85-7307-598.8

Houve sempre interesse por parte de filósofos e cientistas em desvendar os mistérios da mente humana, procurando entender o comportamento e as emoções na busca de possíveis fatores que justificassem o seu funcionamento nos estados fisiológicos e patológicos, fossem esses ligados a problemas internos (biológicos) ou externos (ambientais e psicossociais). Até bem pouco tempo, termos como transtornos de origem orgânica; psicorreativa e endógena predominavam na linguagem psiquiátrica, mas, devido às suas definições imprecisas e sua pouca utilidade na prática clínica, foram caindo em desuso. Recentemente, termos como predisposição ou vulnerabilidade biológica têm sido atribuídos ao fator biológico (genético ou adquirido), elemento essencial para o desenvolvimento de transtornos mentais, sejam esses desencadeados ou não por fatores sociais estressantes.

No livro "Bases Biológicas dos Transtornos Psiquiátricos", subdividido em 20 capítulos, temos inicialmente a satisfação de rever as bases anatômicas e fisiológicas que permeiam o funcionamento do sistema nervoso central (SNC), com uma revisão clara e objetiva que possibilita ao leitor uma melhor compreensão das principais teorias biológicas relativas aos transtornos psiquiátricos. Na leitura dos quatro primeiros capítulos, observamos o quanto é importante o conhecimento da estrutura e do funcionamento do sistema nervoso, levando em consideração as suas bases bioquímicas, a sua fisiologia, e os seus correlatos químicos. Encontramos, também, o que há de mais recente sobre o papel dos neurotransmissores e, principalmente, dos neuropeptídeos, substâncias que têm sido alvo de atenção na gênese das doenças mentais. Nessa linha de pesquisa, os autores relatam os resultados de estudos que mostram alterações das concentrações de colecistoquininas, somastostina eneuropeptídeo Y em áreas cerebrais distintas de pacientes com depressão, transtorno obsessivo-compulsivo (TOC), ansiedade, anorexia nervosa, entre outras enfermidades. Esses achados, embora não sejam ainda conclusivos, são extremamente importantes, pois trazem novas perspectivas na elaboração de fármacos que possam agir em áreas e sistemas diferentes dos já relatados até então e, quem sabe, até melhorar o prognóstico dos transtornos refratários, cujos resultados terapêuticos tanto nos frustram na atualidade.

Nos capítulos 5, 6 e 7 são abordados temas sobre os aspectos imunológicos, neuroendócrinos e a neurobiologia da memória, ressaltando a importância da interação entre o sistema nervoso e outros sistemas orgânicos. Nessa linha de investigação, as possíveis ligações entre SNC e os sistemas imunológico e endócrino se fundem nas chamadas psiconeuroimunologia e psiconeuroendocrinologia. De fato, os neurotransmissores e as citocinas são substâncias sinalizadoras que possuem receptores em células que pertencem tanto ao sistema nervoso quanto ao imunológico. Os autores descrevem também o papel do SNC na regulação do sistema endócrino e a ação desse no SN. Sendo o cérebro alvo de ações hormonais que podem modificar o comportamento e o humor, o conhecimento dessas interações é fundamental para o entendimento dos transtornos psiquiátricos.

Do capítulo 8 ao 14 e no capítulo 16, são descritas algumas patologias que fazem parte da atual nosologia psiquiátrica, e são relatados os resultados de pesquisa que sustentam as principais teorias sobre as bases biológicas dessas patologias. Exploram-se as descobertas sobre a genética, as alterações estruturais encontradas em algumas doenças mentais, os diversos sistemas de neurotransmissão, seus neurotransmissores e neuromoduladores. Parte desses conhecimentos se devem, a partir da década de 70, ao avanço das neurociências e ao surgimento das técnicas de diagnóstico por imagem do SNC, que permitem a avaliação anatômica e funcional do tecido cerebral "in vivo", por medidas do tamanho, volume, fluxo sangüíneo, metabolismo cerebrais e da densidade de neuro-receptores em diversas regiões do sistema nervoso. Assim, são citadas as alterações estruturais e funcionais do SNC encontradas em pacientes com esquizofrenia, TOC e depressão. Além disso, são relatadas as teorias monoaminérgicas e serotonérgica implicadas nos transtornos do humor; as teorias dopaminérgica e neurodesenvolvimental das psicoses esquizofrênicas e os aspectos obscuros envolvidos na gênese da impulsividade, dos transtornos alimentares e dos transtornos mentais da infância e da adolescência.

No capítulo 14 (Comportamento de Busca e Consumo de Drogas), é interessante enfatizar que o autor descreve de maneira direta e objetiva o envolvimento do sistema límbico, das vias mesolímbicas e mesocorticais e a ação da dopamina nesses circuitos, considerando-os como elementos importantes do complexo biológico responsável pelo comportamento de busca e consumo de drogas. Durante a leitura desse capítulo, os dados apontados nos fazem refletir bastante, tornando fácil a compreensão de uma frase citada na página 172: "A tradicional distinção entre dependência física e psicológica é algo artificial, uma vez que ambas são mediadas por mecanismos neurais". Esse pensamento revela um conteúdo bastante complexo e inovador dentro dessa área, que abala conceitos ainda vigentes de que existem drogas causadoras apenas de dependência psicológica, a exemplo da Cannabis sativa.

No capítulo 15 , lê-se a descrição da fisiopatologia da dor, 
sintoma muito freqüente nos quadros de ansiedade e depressão. Para sua melhor compreensão, são estudados os papéis dos opióides endógenos e de vários neurotransmissores.

Nos capítulos finais (17 a 20), há uma revisão de algumas doenças neurológicas que cursam com as modificações comportamentais e de humor, reforçando ainda mais a correlação entre alterações anatômicas e bioquímicas do SNC com sintomas ditos psiquiátricos. Assim, são relatados as degenerações neurais vistas nas demências e os achados neurofisiológicos e patológicos envolvidos nas dissonias e parassonias. Além disso, são discutidas as bases fisiopatológicas da epilepsia e da doença de Parkinson.

Vale a pena ressaltara que, nesse livro, os aspectos neurobiológicos descritos para as doenças mentais fazem a psiquiatria ressurgir como uma especialidade médica, bem próxima da neurologia, da endocrinologia e das ciências básicas. Constituído de moléculas e tecidos, o cérebro tem sua fisiologia e patologia expressas também por comportamentos e emoções, funções que foram delegadas ao campo da psiquiatria. Isso nos leva a pensar que, sendo o comportamento e as emoções expressões fisiológicas mediadas por circuitos cerebrais, é de se esperar que desregulações nesse nível e sua interação com sistemas periféricos, contribuam efetivamente para as alterações patológicas vistas nos quadros de transtornos do humor e de ansiedade, esquizofrenia e outros, considerados transtornos psiquiátricos.

Resta salientar que, apesar dos avanços alcançados nas últimas décadas, ainda estamos distantes de respostas conclusivas, pois muitas questões permanecem indefinidas e patologias como os transtornos somatoformes, sexuais e de personalidade, continuam sendo um desafio ainda maior. Além disso, o papel dos fatores externos, ambientais e psicossociais no desencadeamento dessas doenças, e da possível interação entre esses fatores com as bases biológicas envolvidas em cada uma delas, precisa de mais esclarecimentos.

Concluindo, o conteúdo desse livro abre, sem dúvidas, caminhos para novas investigações e pesquisas, e aguça o pensamento crítico daqueles que trabalham com as doenças mentais, ou como melhor descreveram os idealizadores dessa obra, com os transtornos psiquiátricos.

Ângela Miranda Scippa

Casa de Saúde Santa Mônica, Salvador, Bahia 